NBER WORKING PAPER SERIES

\title{
WORKER SORTING, COMPENSATING DIFFERENTIALS AND HEALTH INSURANCE: EVIDENCE FROM DISPLACED WORKERS
}

\author{
Steven F. Lehrer \\ Nuno Sousa Pereira \\ Working Paper 12951 \\ http://www.nber.org/papers/w12951
NATIONAL BUREAU OF ECONOMIC RESEARCH
1050 Massachusetts Avenue
Cambridge, MA 02138
March 2007

\begin{abstract}
We are grateful to one anonymous referee, Daniel Parent and seminar participants at the 2003 iHEA Conference and Fudan University for helpful comments and suggestions that have substantially improved the paper. We would also like to thank Kosali Simon for providing code that helped to generate a portion of the dataset used in this study. Lehrer wishes to thank SSHRC for research support. Pereira gratefully acknowledges support from CETE. CETE, Research Center on Industrial, Labour and Managerial Economics, is supported by the Fundacao para a Ciencia e a Tecnologia, Programa de Financiamento Plurianual, through the Programa Operacional Ciencia, Tecnologia e Inovacao (POCTI) of the Quadro Comunitario de Apoio III, which is financed by FEDER and Portuguese funds. The usual caveat applies. The views expressed herein are those of the author(s) and do not necessarily reflect the views of the National Bureau of Economic Research.

(C) 2007 by Steven F. Lehrer and Nuno Sousa Pereira. All rights reserved. Short sections of text, not to exceed two paragraphs, may be quoted without explicit permission provided that full credit, including (c) notice, is given to the source.
\end{abstract}


Worker Sorting, Compensating Differentials and Health Insurance: Evidence from Displaced

Workers

Steven F. Lehrer and Nuno Sousa Pereira

NBER Working Paper No. 12951

March 2007

JEL No. I11,J30

\begin{abstract}
This article introduces an empirical strategy to the compensating differentials literature that i) allows both individual observed and unobserved characteristics to be rewarded differently in firms based on health insurance provision, and ii) selection to jobs that provide benefits to operate on both sides of the labor market. Estimates of this model are used to directly test empirical assumptions that are made with popular econometric strategies in the health economics literature. Our estimates reject the assumptions underlying numerous cross sectional and longitudinal estimators. We find that the provision of health insurance has influenced wage inequality. Finally, our results suggest there have been substantial changes in how displaced workers sort to firms that offer health insurance benefits over the past two decades. We discuss the implications of our findings for the compensating differentials literature.
\end{abstract}

Steven F. Lehrer

School of Policy Studies

and Department of Economics

Queen's University

Kingston, Ontario

K7L, 3N6 CANADA

and NBER

lehrers@post.queensu.ca

Nuno Sousa Pereira

Department of Economics, University of Porto

Rua Dr. Roberto Frias

4200-464 Porto, Portugal

npereira@fep.up.pt 


\section{Introduction}

Without a national health insurance system most Americans receive health benefits from their employers. As recent years have been characterized by rapid inflation in health care costs and health insurance premiums, ${ }^{1}$ there are increasing reports that employers have either reduced or even stopped offering coverage, increasing the ranks of the uninsured. ${ }^{2}$ In aggregate, the percentage of workers with employment-based health insurance has dropped from $70.0 \%$ in 1987 to $59.8 \%$ in 2004 .

Economists generally argue that profit maximizing employers would respond to the costs associated with the provision of health insurance by reducing wages, thus maintaining the total reward paid to the employees. Whether employers truly adjust wages for the provision of health insurance is a long-standing question in health economics. Evidence of a wage / fringe benefit tradeoff has been difficult to establish empirically, in part because jobs that offer health insurance may differ substantially from those where this benefit is not provided. ${ }^{3}$ Empirical researchers have traditionally attempted to answer this question using wage regressions. Researchers arrive at conclusions by examining the sign and significance of the estimated coefficient on the health insurance receipt variable. Studies generally differ in the source of variation used to identify health insurance receipt in these regressions. The early literature on this topic typically did not explicitly contain a discussion of the source of variation in the health insurance variable and researchers implicitly assume that employees have implicitly made these choices when accepting a job

offer. Using cross-sectional data researchers typically recover wrong signed estimates of the compensating wage differential particularly if they ignore the inherent endogeneity of health insurance receipt. Longitudinal data that explicitly account for individual specific permanent unobserved heterogeneity have also been used, yet results from these studies also do not support the theoretical prediction of a significant negative compensating differential. ${ }^{4}$ To identify the tradeoff, many of these studies must overcome the endogeneity of job switching. In particular, if job lock is an important factor in the labor market, then 
the sample used in the analysis for identification will disproportionately contain those individuals who do not feel locked into their job, possibly attributable to a lower valuation of health insurance. To overcome this empirical challenge, Simon (2001) uses panel data on displaced workers who switch jobs for exogenous reasons, but also fails to find evidence of compensating wage differentials, which she attributes to difficulty in empirically dealing with the heterogeneity of job-skill matching.

In contrast, a recent literature attempts to use a credible source of variation in the costs of health insurance, which is arguably exogenous to workers employment decisions, to identify whether these additional costs are borne by workers. These studies generally find evidence consistent with the theory. For example, Gruber (1994), exploiting changes in state legislation that made coverage for childbirth a mandatory part of all health insurance policies, finds that the wages of workers expected to benefit from this policy were shifted down by 59-90\%. Sheiner (1999) uses variation in health care costs across cities and finds that older workers in cities with higher health costs earn lower wages. While these studies are unable to disentangle whether the shifting of health insurance costs is on the group at the workplace or on the individual, Pauly and Herring (1999) find a flatter wage-tenure profile among job-insured workers presenting evidence consistent with an individual wage adjustment for health insurance.

In his review of the compensating differentials literature, Pauly (2001) sustains the existing studies do not provide compelling evidence, either in favor, or against the existence of this trade-off. The interest in achieving a more solid answer to whether this trade-off truly exists is unquestionable, given the numerous implications for public policy. To shed light on this issue as well as provide an explanation for the diversity of the findings in this literature, we introduce a new panel data estimator to the health economics literature and reexamine the experience of displaced workers who change jobs for arguably exogenous reasons over a eighteen year period. The estimation strategy originally developed in Lemieux (1998) allows observed and unobserved characteristics to be rewarded differently 
in firms that provide and do not provide health insurance, and it generates estimates robust to both employer and employee selection on unobservables. Estimates from our model are used to first, evaluate the existence and robustness of any potential wage and health insurance trade-off and second, to decompose the wage gap between firms that offer and do not offer health insurance. Our approach additionally allows us to test implicit assumptions underlying conventional empirical approaches used in the health economics literature.

Examining the wage decomposition provides an opportunity to understand how displaced workers sort into new positions in the labor market. The equalizing differences literature that underlies the wage health insurance trade-off implicitly assumes that workers should sort into jobs with different attributes based on their preferences for those attributes. ${ }^{5}$ In contrast, comparative advantage would suggest that workers sort into firms or sectors in which they would perform relatively better than other potential employees in the labor market. Understanding the sorting process potentially could yield insights into how the labor market functions and how inequality develops. ${ }^{6}$ For example, if the underlying distribution of skills among displaced workers were stable over time, any changes in the manner in which these workers sort to new jobs would lead to a potentially different allocation of these skills across firms over time. ${ }^{7}$

While it is well known that displaced workers experience large and persistent earnings loss, ${ }^{8}$ this group is becoming a topic of increased policy relevance. Since many Americans are a pink slip away from losing their health insurance coverage ${ }^{9}$ numerous policies have been introduced in the last five years to promote the continuation of health insurance coverage for displaced workers. For example, the Health Coverage Tax Credit introduced federally in 2002 covers 65 percent of the premium amount paid by eligible displaced individuals for health insurance coverage, where eligibility is primarily based on prior industry. By reducing the costs of health insurance while unemployed, these polices may alter the search behavior for newly displaced workers by increasing the take-up 
of unemployment benefits and the length of unemployment spells. In addition, several individual states have introduced health plans for displaced workers and new policies are being continually debated at both the federal and state level. To provide some guidance for policymakers regarding the impacts of such programs, we use our data and estimates from the wage decomposition to ascertain whether there have been any changes in how displaced workers search for and sort into a new job following displacement (based on the provision of employer provided health insurance) over the last two decades.

Our analysis yields three major findings for the health economic literature on the impacts of employer based health insurance provision.

1) We find that the diversity of results in the health economics literature on the existence of a compensating wage differential may be more a consequence of imposing too stringent assumptions on the empirical model rather than a failure of the underlying theory. Our empirical estimates reject assumptions that underlie single index control function, OLS, matching, fixed effects and first difference strategies. Specifically, we clearly reject the assumptions that permanent individual specific unobserved (to the analyst) heterogeneity is constant and that selection of jobs by displaced workers can be explained by variables observed to the analyst. Further, since selection of this new job is based in part on factors unobserved to the analyst, our results suggest that this does not operate exclusively on the workers' side of the labor market but also affects hiring decisions by firms. Researchers in this area must account for both employee and employer decisions regarding employer provision of health insurance.

2) Our empirical results indicate substantial changes have occurred over the past two decades both in how displaced workers sort across firms when seeking reemployment and how firms select workers for employment. We observe that, if on one hand, the importance of selection bias in explaining the unadjusted wage gap has diminished by over $40 \%$, on the other hand, the portion of this bias due only to unobserved (to the analyst) characteristics, such as ability or innate health status has more than doubled. 
Finally, we find that recently displaced workers are searching nearly three weeks longer for jobs that provide health benefits, suggesting that those who need health insurance shop for it.

3) We find that the provision of health insurance has substantially influenced wage inequality. Similar to the large established literature that has explored the determinants of wage structure in the U.S. labor market, ${ }^{10}$ we estimate that, in the past decade, firms that provide health insurance are offering increasingly larger returns to observed individual characteristics. In particular, we find that there is nearly a 30\% increase in the returns to a college education in firms that provide health benefits. Residual wage dispersion has also increased over the past two decades as our results indicate that the return to unobservable skills, such as motivation, innate health status or cognitive ability has risen.

While we do not find any evidence of a health insurance compensating wage differential, we find that the effect of health insurance on wage of workers in firms providing health insurance has increased by $50 \%$ between decades. In addition, we present evidence that the role of unobserved characteristics is increasingly affecting the dispersion of wages between sectors. Our results suggest that a larger fraction of the displaced work force is seeking jobs with health insurance benefits and, faced with a more heterogeneous pool of applicants, employers in the health insurance sector are increasingly rewarding observed skills. We hypothesize that the inability to identify the impact of health insurance on wage levels is likely a consequence of omitting firm characteristics that arise from aggregate worker sorting rather than the heterogeneity of individual job-skill matching.

The rest of the paper is organized as follows. In the next section, we introduce the economic model and empirical method that we employ to estimate the parameters of the model. Section 3 describes the data used in our analysis. Estimates of our model and other empirical results are presented and discussed in section 4. A concluding section discusses what our findings on worker sorting imply for the compensating differentials literature and suggests avenues for further research. 


\section{Economic Model}

We consider a two sector model of the economy with differences in the provision of health insurance. The expected log wage of worker $i$ at time $t$ in the sector that does not offer health insurance is given by

$$
\ln w_{i t}^{N}=\alpha^{N}+x_{i t}^{\prime} \beta^{N}+\varepsilon_{i t}^{N}
$$

where $x_{i t}$ is a vector of observed (to the market and the econometrician) characteristics. The corresponding log wage for someone in the health insurance sector is

$$
\ln w_{i t}^{H}=\alpha^{H}+x_{i t}^{\prime} \beta^{H}+\varepsilon_{i t}^{H}
$$

where $\alpha^{H}=\alpha^{N}+H I_{i t}^{\prime} \beta^{H I}$, and $H I_{i t}$ is an indicator variable that equals one when the individual is employed in the sector of firms that offers health insurance. We explicitly permit the returns to observed and unobserved characteristics to vary across sectors. The residuals in each sector follow a one way error component structure

$$
\begin{aligned}
& \varepsilon_{i t}^{N}=\theta_{i}^{N}+\eta_{i t}, \eta_{i t}{ }^{\sim} \operatorname{IID}\left(0, \sigma^{2}\right) \\
& \varepsilon_{i t}^{H}=\theta_{i}^{H}+\eta_{i t}, \eta_{i t}{ }^{\sim} \operatorname{IID}\left(0, \sigma^{2}\right)
\end{aligned}
$$

where $\theta_{i}^{N}$ and $\theta_{i}^{H}$ are the return of the individual time invariant unobserved (to the econometrician) characteristics in the respective sectors. ${ }^{11}$ We do not impose any restrictions on the joint distribution of $\left(\theta_{i}^{N}, x_{i t}\right)$ or $\left(\theta_{i}^{H}, x_{i t}\right)$, allowing for arbitrary correlations. This formulation allows for both absolute advantage and comparative advantage since individual heterogeneity can respectively affect both the intercept and slope of the wage function. ${ }^{12}$

As in the program evaluation literature, an individual's actual wage can be expressed as a function of two potential wages via the following equation

$$
\ln W_{i t}=H I_{i t} \ln w_{i t}^{H}+\left(1-H I_{i t}\right) \ln w_{i t}^{N}+\nu_{i t}
$$


where $v_{i t}$ is an idiosyncratic error term that captures differences between the observed wage and the wage expected on the basis of skills and sector choice. Substituting equations (1) - (3) into equation (4) yields

$$
\ln W_{i t}=\alpha^{N}+x_{i t}^{\prime} \beta^{N}+\theta_{i}^{N}+H I_{i t}^{\prime}\left[H I_{i t}^{\prime} \beta^{H I}+x_{i t}^{\prime}\left(\beta^{H}-\beta^{N}\right)+\theta_{i}^{H}-\theta_{i}^{N}\right]+\xi_{i t}
$$

where $\xi_{i t}=\eta_{i t}+v_{i t}$. Lemieux (1998) demonstrates that the wage differential between sectors can be decomposed into two main terms, given by

$$
W G=\left[\beta^{H I}+\bar{x}_{H}^{\prime}\left(\beta^{H}-\beta^{N}\right)+(\psi-1) \bar{\theta}_{H}\right]+\left[\left(\bar{x}_{H}^{\prime}-\bar{x}_{N}^{\prime}\right) \beta^{N}+\left(\bar{\theta}_{H}-\bar{\theta}_{N}\right)\right]
$$

where $\beta^{H I}$ is the direct compensating wage differential. The first term in square brackets of equation (6) reflects the mechanism by which workers pay for receiving health insurance, while the second term in square brackets reflects average skill differences between the workers that select jobs that offer health insurance and the workers that prefer jobs without health insurance as part of the compensation package. Similarly, the variance of the wage gap can be decomposed into three components, given by

$$
\begin{aligned}
V G= & {\left[\left(\beta^{H \prime} \Sigma_{X H} \beta^{H}-\beta^{N \prime} \Sigma_{X N} \beta^{N}\right)+\left(\psi^{2}-1\right) \sigma_{\theta H}^{2}+2\left(\psi \beta^{H}-\beta^{N}\right)^{\prime} \Sigma_{X \theta_{H}}\right]+} \\
& {\left[\beta^{H \prime}\left(\Sigma_{X H}-\Sigma_{X N}\right) \beta^{H}+\left(\sigma_{\theta H}^{2}-\sigma_{\theta N}^{2}\right)+2 \beta^{H \prime}\left(\Sigma_{X \theta_{H}}-\Sigma_{X \theta_{N}}\right)\right]+\left[\sigma_{H}^{2}-\sigma_{N}^{2}\right] . }
\end{aligned}
$$

The components in square brackets respectively reflect, the impact of health insurance on the dispersion of wages in that sector, the differential heterogeneity in workers between sectors, and the difference in residual variance.

Unlike control function or selection correction estimation strategies, this model permits selection of workers to a job to be on both sides of the market. Employers in the health insurance sector may prefer to select individuals who have higher values of $\theta_{i}^{H}$, which could represent among other factors ability, motivation and health status. This creates a wedge in the labor market as individuals with low values of $\theta_{i}^{H}$ may seek jobs with health insurance provision, but employers prefer healthier individuals and / or individuals with higher ability who can respectively help reduce the cost of providing health insurance and / or potentially increase output. ${ }^{13}$ 


\subsection{Empirical Method}

To estimate the structural parameters in equation (5), Lemieux (1998) proposes the following GMM procedure. A common unobserved attribute $\theta_{i}$ that is a function of $\theta_{i}^{H}$ and $\theta_{i}^{N}$ is defined and included in equation (5), so it can be reexpressed as ${ }^{14}$

$$
\ln W_{i t}=\alpha^{N}+x_{i t}^{\prime} \beta^{N}+\theta_{i}+H I_{i t}^{\prime}\left[H I_{i t}^{\prime} \beta^{H I}+x_{i t}^{\prime}\left(\beta^{H}-\beta^{N}\right)+(\Psi-1) \theta_{i}\right]+\xi_{i t}
$$

where $\Psi$ is a coefficient vector that captures differentials rewards to unobserved skills across sectors. Similarly, the wage equation in period $t-1$ can be rearranged as a function of $\theta_{i}$, yielding

$$
\theta_{i}=\frac{\ln W_{i t-1}-\alpha^{N}+x_{i t-1}^{\prime} \beta^{N}-H I_{i t-1}^{\prime}\left[H I_{i t}^{\prime} \beta^{H I}\right]+H I_{i t-1}^{\prime} x_{i t-1}^{\prime}\left(\beta^{H}-\beta^{N}\right)-\xi_{i t-1}}{1+H I_{i t-1}(\Psi-1)}
$$

Direct substitution of equation (9) into equation (8), quasi differences and removes $\theta_{i}$ from the wage equation at time $t$. This yields

$$
\ln W_{i t}=g\left(z_{i t}\right)+\xi_{i t} \frac{1+H I_{i t}(\Psi-1)}{1+H I_{i t-1}(\Psi-1)}\left\{\ln W_{i t-1}-g\left(z_{i t-1}\right)-\xi_{i t-1}\right\}
$$

where $g\left(z_{i s}\right)=\alpha_{s}^{N}+x_{i s}^{\prime} \beta^{N}+H I_{i s}^{\prime}\left[H I_{i t}^{\prime} \beta^{H I}+x_{i s}^{\prime}\left(\beta^{H}-\beta^{N}\right)\right]$. Direct non linear least squares estimation of equation (10) will yield biased and inconsistent parameter estimates of $\Psi$, which stems from the correlation of the lagged dependent variable $\left(W_{i t-1}\right)$ with the transformed residual $\left(\xi_{i t}+\frac{1+H I_{i t}(\Psi-1)}{1+H I_{i t-1}(\Psi-1)} \xi_{i t-1}\right) \cdot{ }^{15}$

Consistent estimates of equation (10) can be obtained by GMM provided one has access to an instrumental variable for $W_{i t-1}$. While instruments could be chosen using the strict exogeneity identification assumption for estimation of traditional panel data equations, we use annual state level information on the previous job's union coverage rate at the industry level. We hypothesize that industries with higher union coverage rates should be associated with higher wages in the jobs prior to displacement. At the firm level, Buchmueller et al. (2002) suggest that reduction in union density accounts for 20$35 \%$ of the reduction in health insurance coverage. Further, it is unlikely that these state 
level aggregate measures are related to the individual specific time varying unobservables in equation (10). ${ }^{16}$

To identify the structural parameters, the unobserved time invariant individual specific component of the residual must be normalized to zero. Formally, this demands imposing the restriction

$$
\frac{1}{T * N} \sum_{i} \sum_{t} \theta_{i t}=0
$$

as a constraint on the optimization of equation (10), and ensure $\theta_{i t}$ satisfies equation (9). With estimates of the structural parameters, the wage gap (as expressed in equation (6)) can be decomposed into the true effect of health insurance on wages and differences in the characteristics of workers between sectors. ${ }^{17}$

\section{Data}

The data used in this study comes from the Displaced Worker Supplement (DWS) of the Current Population Survey (CPS). The CPS is a comprehensive, cross-sectional survey of approximately 50,000 households in the United States. The DWS is a biennial supplement to the CPS presenting a nationally representative cross-sectional survey of displaced workers (those who have lost jobs because of plant closings, business failures, and layoffs) and includes retrospective data several years prior to the administration of the survey. Among these workers, their job loss resulted from exogenous decisions that were unrelated to both their particular performance and preferences over the structure of the compensation package. ${ }^{18}$ Most important for this study, the DWS contains information on wage rates and health insurance status, both on their job prior to and following

displacement. ${ }^{19}$ The DWS also includes detailed information on demographic characteristics and individual labor market variables pre and post displacement for a large sample of displaced workers.

We use data from DWS supplements collected from 1984 to 2002 and largely follow the 
sampling criteria used in Simon (2001), deleting observations where workers were either employed part-time, self-employed or held seasonal jobs. ${ }^{20}$ Relative to the nationally representative CPS, displaced workers are disproportionately male, previously employed in semi-skilled blue collar labor and are less likely to be a college graduate (particularly in the 1980s). The data was supplemented with information from both the January and March CPS to obtain additional controls in our analysis. For instance, tenure information comes from the January Basic dataset, and is calculated as the number of years the individual have been employed in the current job.

Despite the many advantages of using the DWS data for estimating wage/health insurance trade-offs, there are a number of limitations that should be noted. First, the DWS treats health insurance as a homogeneous good and there are many dimensions across which plans vary such as annual deductible, and co-payments. We cannot accurately measure the cost of health insurance or the part paid by the employee. ${ }^{21}$ Second, the data set lacks information on other fringe benefits such as employer provided pension plans, employer provided retirement health insurance that are likely correlated with health insurance benefits. Third, data on pre-displacement firm characteristics such as firm size and profitability are not collected. As we will discuss, this limitation is likely the most severe. Fourth, the data lacks information on skill transferability. Fifth, the survey only asks whether a person has private health insurance coverage but does not ask the source that provides these benefits which could lead to biases, particularly for individuals that have spouses with family health benefits. To mitigate these biases we use the March CPS supplement as it contains more detailed information on whether employer insurance is in their own name allowing us to verify whether this insurance is really from their own primary employer. Unfortunately, due to the rotational structure of the CPS we lose approximately $43 \%$ of our sample when we match respondents. ${ }^{22}$

An additional potential concern with the DWS is whether the responses subjects made are valid or subject to recall error, since it relies heavily on retroactive questions. Oyer 
(2004) conducts a fascinating examination of the presence of recall error in the DWS and finds that, while displaced workers report the reason for job loss quite accurately, respondents may overstate only their pre-layoff wages. Overall, he concludes that DWS recall error is not dramatic and that it has little, if any, relationship with other variables in the survey. In our analysis, we use an instrumental variables procedure to correct for the endogeneity of pre-displacement wages, which should further reduce concerns of biases attributable to measurement error.

Another important feature of the DWS worth noting is that there was a change in the recall period for which information on job loss was collected. Until 1994 workers were asked if they had lost a job in the last five years, while, after 1994, the time frame was limited to three years only. This change, together with a shift in the political and health sector environment, will permit us to use the samples pre and post 1994 separately in our analysis. $^{23}$

Table 1 presents summary statistics for portions of the sample used in this study. In the top panel, the full sample is divided into four groups, based on their health insurance provision pre and post displacement. The majority of the sample (64\%) corresponds to workers that received health insurance on both jobs and are called "Always". Workers gaining health insurance following displacement constitute $14 \%$ of the sample, similarly $12 \%$ of the sample lost health insurance benefits with displacement and the remaining $10 \%$ did not receive health insurance at either job.

There are substantial differences between these groups in terms of their level of education, earnings, race and probability of switching industry and occupation following displacement. The two groups of the sample that did not receive health insurance prior to displacement have, on average, a lower level of education, a lower pre-displacement wage and are more likely to be African American than groups which received health insurance in both periods. Further, losing health insurance following displacement is associated with both large wage losses and a higher likelihood of switching industry or occupation. Notice 
that jobs pre and post displacement that offer health insurance provide higher wages. ${ }^{24}$ The usual explanation for this finding is that those employed in good jobs are likely to differ from those in worse jobs on both observable and unobservable characteristics. ${ }^{25}$

In the second part of Table 1, we examine how the characteristics of the sample differ between 1984-92 and 1994 onwards. Notice that, after 1994, the displaced workers are more educated, slightly older and contain more females. Further, displaced workers after 1994 are less likely to have children or receive unemployment benefits following displacement. While age and education would suggest an increase in the propensity to receive health benefits, not having children could serve to reduce the benefits from receiving health coverage from an employer. Interestingly, more workers in our sample over the last decade received health insurance following displacement, which is the opposite of the pattern in the general labor market.

\section{Results}

GMM estimates of equation (10) are displayed in Table 2. The full sample is presented in column one, while columns two and three respectively present the subsamples for the periods 1984-92 and 1994-2002. Health insurance is not significantly related to workers wage in any of the samples. Only in the most recent decade is the sign of the coefficient estimate consistent with the compensating wage differential theory. While this result does not differ from most estimates found in the compensating differential literature, our empirical strategy allows us to test some implicit assumptions within that literature.

The assumption that unobserved heterogeneity has a constant impact across sectors underlies fixed effects, first difference and difference in difference propensity score matching estimators. Our model treats the returns to this unobserved term in a more flexible manner and parameter estimates of $\Psi$ are presented in the second row of Table 2 . For the

full pooled sample (presented in column one), $\Psi$ is statistically different from one at the $1 \%$ confidence level, suggesting that we can directly reject the assumption that $\theta_{i}^{N}=\theta_{i}^{H}$, 
implying that unobserved skills are rewarded differently in the two sectors of the economy. However, the constraint that $\Psi$ is statistically different from one cannot be rejected at the $1 \%$ confidence level for the 1984-1992 sample in the second column. The presence of this omitted selection effect may be biasing the impacts reported in several longitudinal studies. This suggests that, conditional on characteristics, some workers may have a comparative advantage in the health insurance sector, which, based on the differences in the magnitude of the coefficient between columns two and three, appears to be of increasing importance in recent years.

Further, consistent with earlier studies on the incidence of health insurance costs on worker wages, there are substantial differences in how characteristics are rewarded across the two sectors. ${ }^{26}$ There are lower returns to pre-displacement tenure and being African American in firms that provide health insurance benefits. On the other hand, being married, being older and being more educated yield higher returns in firms that offer these benefits. While the positive return to marriage decreased slightly between the sample periods, there was an approximate $27 \%$ increase in the returns to a college education relative to 12 years of education or less in firms that provide benefits. In total, the gap in the health insurance sector between college degree holders and individuals who have fewer than 12 years of education rose over $30 \%$, from 0.538 to 0.716 . The wage gap between males and females became smaller in both sectors following 1994. It is interesting to note that while older workers received significant wage decreases in the sector that does not provide health insurance prior to 1994, the relationship becomes statistically insignificant for the period between 1994 and 2002. Finally, while the differential to being African American increased after 1994, there is no additional wage offset in the health insurance sector.

The estimates from Table 2 are used to decompose the unadjusted health insurance wage gap into a true effect of health insurance on wages and a selection bias component following equation (6). The first column of Table 3 presents the decomposition for the 
entire sample period. Health insurance has substantial impacts on workers in the health insurance sector that primarily operate through differential returns to observed characteristics. For the full sample, over $80 \%$ of the effect of health insurance on workers in the health insurance sector operates through this channel. Further, the role of unobserved factors is limited.

The change in the components of the wage decomposition between 1984-1992 and 19942002 in columns two and three of Table 3 presents several interesting findings. Between these periods, the unadjusted wage gap has grown, which is, in part, (and consistent with Farber and Levy (2000)) due to firms which stopped offering benefits over this time period tended to be clustered in low-paying industries. The prime component that explains the growth in the unadjusted wage gap between sectors is the substantial increase in the returns to observed skills. The returns to these skills have more than doubled between periods. Examining the second and third columns of Table 2, it is clear that these rewards are being driven by the increased returns to a college education as well as returns to age, which may proxy for total labor market experience.

Not only did the returns to observed skills rise across periods, but there was also a large decrease in the amount of the gap that is attributable to selection bias. Overall selection bias dropped by nearly 30\%, from 0.179 to 0.127 driven by the differences in observed skills across sectors. Information on the portion of selection bias attributable to observables and unobservables is presented in rows six and seven of Table 3, respectively. Selection bias due to unobservables measures the similarity in average unobserved attributes between workers in the two sectors (i.e. $\bar{\theta}_{H}$ and $\bar{\theta}_{N}$ ). The fifth row of Table 4 indicates that the gap in these attributes has become smaller between the two sub-sample periods. On average, workers employed in firms that offer health insurance have larger values associated with unobserved attributes related to productivity $\left(\bar{\theta}_{H}\right)$ than those employed in firms that do not offer these benefits $\left(\bar{\theta}_{N}\right)$. Yet, the portion of selection bias due to unobserved skills that cannot be accounted for by estimators such as OLS and matching rose by nearly $15 \%$ 
between decades. Since $\bar{\theta}_{H}>\bar{\theta}_{N}$, and the health insurance wage gap is slightly higher for individuals with higher unobserved skills, we would predict that the OLS estimates of the compensating wage differential would be biased upwards. ${ }^{27}$

Our estimates are also used to decompose the unadjusted gap in variance of wages between sectors. The results are presented in Table 4. The unadjusted gap appears small and indicates that health insurance reduces the dispersion of wages between sectors. ${ }^{28}$ While the overall size of the difference between the variance of wages between sectors becomes smaller after 1994, the role of the two major components of the decomposition, the effect of health insurance on health insurance workers and selection bias, increases markedly. In particular, the portion of selection bias due to differences in unobserved skills and the direct effect of both observed and unobserved skills on the variance of wages increase by over $50 \%$ between the periods. While workers appeared on average to be increasingly more homogeneous across sectors in Table 3, the results in the fifth row suggest that there is substantially more heterogeneity in the unobserved skills of individuals working in the health insurance sector (relative to the other sector) after 1994.

In Table 3, we found that employers in the health insurance sector did not pay workers differently on the basis of these unobserved skills and increasingly rewarded observed skills. If employers assume that observed productivity skills are highly positively correlated with unobserved skills it may be the case that this heterogeneity has led employers to increase the reward to observed characteristics. While this should suggest that the variance in the wages between the sectors would increase across the two sample periods, there is, as reported in the second row of Table 4, a large offset since unobserved skills have significantly reduced the variance of wages for health insurance workers in the health insurance sector.

The findings in Table 4 are also consistent with selection operating on both sides of the labor market, which rules out traditional selection correction or control function 
estimators. The negative covariance in the sixth row indicates that observed and unobserved skills are positively correlated in the sector that does not provide health insurance, but negatively correlated in the health insurance sector. This is consistent with positive selection among workers with low unobserved skills in the health insurance sector and negative selection among workers with high observed skills. This selection becomes more important over time as the size of the covariance terms increases by over $50 \%$ between the sample periods. This positive selection may be a result of increased worker shopping for positions that offer health insurance benefits and may have partially contributed to the recent health insurance cost spiral for employers.

In our estimation, we used the average unionization rate in the industry the worker was employed in pre-displacement to instrument for previous period wage. To assess the suitability of our instrument we consider a simple OLS regression of the first stage regression and run an F-test for the joint significance of the instrument. The results are presented in Table 5 for the case with information on unionization coverage rates. We ignore the specifications with interaction terms included in the instrument set since overidentification tests occasionally reject the hypothesis that the instruments are valid. ${ }^{29}$ Coefficients on the instrument and exogenous regressors in both columns are reasonable in sign and magnitude. The instruments are statistically significant predictors of predisplacement wages and the F-statistics on its significance is respectively above current cutoffs (i.e. Staiger and Stock (1997)) for weak instruments for both the full sample and pre-1994 sample.

Since the reliability of our estimates depends directly on the validity of our instrument, the low F-statistic over post 1994 period is a concern, since it may indicate weak identification. Weak identification could result in i) the GMM estimates being inconsistent and biased towards the NLLS estimates, ${ }^{30}$ and ii) the test statistics for inference are inaccurate. Regarding the first problem, not only is the coefficient on the instrument reported in Table 5 significant at the $1 \%$ level but also a Hausman test rejects the consistency of the 
NLLS estimates. Further, we attempted to correct the statistical inference problem using Moreira (2003) conditional approach to construct tests of coefficients based on the conditional distributions of nonpivotal statistics. If the instruments have low strength then the confidence intervals should increase relative to those based on standard asymptotic theory. We find that the length of the $95 \%$ confidence interval increased by only $16.8 \%$, a small margin which increases our confidence in the validity of the instrument. Taken together, these diagnostics suggest that it is unlikely that the second period estimates are due to a poor instrument.

An additional concern is that the average unionization rate in the industry the worker was employed in pre-displacement may not be a suitable instrument, since it is related to an individual's own union status, which is implicitly contained in the residual. To examine the robustness of our results, we replicated the full analysis accounting for individual union status both pre and post displacement for the portion of the sample that provided this information and our results did not change neither qualitatively, nor quantitatively. ${ }^{31}$

\subsection{Worker Sorting and Health Insurance}

\subsubsection{Are Search Patterns in the DWS Consistent with Increased Worker Sorting?}

Testing directly for worker sorting is difficult without more detailed information on firms. To present additional evidence that is consistent with the hypothesis of an increase in worker sorting we contrast job search patterns between post displacement health insurance receipt conditional on pre displacement health insurance receipt over time. We hypothesize that if worker shopping has increased then individuals who gain health insurance following displacement should have longer searches. Due to the sampling criteria change after 1994, it is hard to compare these past histories between the two sampling periods and the results should be biased against our hypothesis, since longer job searches are possible in the earlier data collections. 
To draw comparisons we consider a difference in difference strategy. First, we contrast the length of job search between new health insurance recipients with individuals who never receive health insurance. Second, we compare individuals who receive health insurance pre and post displacement to individuals who lose health insurance after displacement. The implicit assumption underlying this strategy is common trend, that is that any changes in outcomes between these groups must be the result of health insurance status post displacement. Essentially we estimate a regression model of the form

$$
Y_{i t}=\gamma_{1}+x_{i t}^{\prime} \gamma_{2}+H I_{i t}^{\prime} \gamma_{3}+\left(H I_{i t} * t_{2}\right)^{\prime} \gamma_{4}+t_{2}+v_{i t}
$$

where $Y_{i t}$ is weeks of job search and $t_{2}$ is a dummy for the period after 1994. If $\gamma_{4}>0$, this would support the hypothesis that individuals who receive health insurance following displacement post 1994 are associated with an increase in job search. We estimate equation (12) separately for individuals who had health insurance prior to displacement and for those who did not have these benefits.

Column one of Table 6 presents differences in the experiences between jobs for individuals who lost health insurance following displacement versus those who had health insurance in both jobs. Consistent with a story of increased job search, workers who found employment in firms that offered health insurance search for approximately three more weeks. Since the average job search in this period is 10.586 weeks, this is an increase of approximately $30 \%$ from the mean. However, the results presented in column two that compare new health insurance recipients to individuals who never received health insurance, do not find any significant differences in length of job search after 1994 for new recipients. As shown in Table 1, on average, the workers who gain health insurance post displacement have the shortest searches. Not surprisingly, older workers search longer in both subsamples as do workers with more tenure on the earlier job and less education, as they may have been most scarred from the displacement. 


\subsubsection{Is the link between unobserved productivity attributes and health in- surance coverage homogenous?}

Understanding if individuals with lower unobserved productivity attributes are increasingly sorting to jobs that provide health insurance benefits is clearly a question of policy interest. While our data cannot directly address whether these individuals truly have lower health status to determine if sorting may have contributed to the recent rise in health insurance costs, we can examine whether the unobserved productivity characteristics of workers are increasingly correlated with post-displacement jobs that provide benefits. We consider estimation of

$$
\widehat{\theta}_{i}=\gamma_{1}+H I_{i t}^{\prime} \gamma_{2}+\left(H I_{i t} * t_{2}\right)^{\prime} \gamma_{3}+t_{2}^{\prime} \gamma_{4}+v_{i t}
$$

where $t_{2}$ is a dummy for the period after 1994 and $\widehat{\theta}_{i}$ is the predicted individual time invariant characteristics obtained from OLS estimation of the following equation

$$
\theta_{i t}=\delta_{1}+\theta_{i t-1} \delta_{2}+\varpi_{i t}
$$

where $\varpi_{i t}$ is a random unobservable, $\theta_{i t}$ is calculated using equation (9) and GMM estimates from the first column of Table $2 .^{32}$ Table 7 present estimates of equation (13) based on samples defined by pre-displacement health insurance status and age.

For the full sample in column one, we notice that, while health insurance is associated with higher unobserved attributes $\left(\gamma_{2}>0\right)$, the recipients in the second time period actually have lower values of $\theta_{i}\left(\gamma_{4}<0\right)$. This indicates that individuals who have health insurance in the second period have on average values of $\theta_{i}$ that are 0.043 lower then the earlier time period. This effect is large and approximately equal to a $5 \%$ of the standard deviation of $\theta_{i}$. Columns four and seven present evidence that the magnitude of this negative impact is not heterogeneous with respect to whether or not an individual had health insurance pre-displacement. When we examine subsamples that are defined by age several interesting patterns emerge. The estimates of $\gamma_{3}$ in the third, sixth and 
ninth columns demonstrate that there is a large decrease in $\theta_{i}$ associated with receiving health insurance after 1994 for workers above 45. In contrast workers under the age of 45 either have $\gamma_{3}$ estimates that are statistically insignificant (column eight) or of limited economic significance (columns two and five). The results in Table 7 suggest that while on average unobserved productivity attributes are greater in the period following 1994, there is a significant negative association between these unobserved productivity attributes and receiving employer provided health insurance after 1994. This effect is driven by workers that are at least 45 years of age. ${ }^{33}$

Taken together, the results in this section suggest that, among individuals who have health insurance in the period post 1994, they have i) lower values of $\theta_{i}$, unobserved productivity attributes that may include health status, and ii) the search for another position that provides these benefits lasted an additional two weeks. We hypothesize that these individuals are most likely familiar with health insurance benefits and increasingly seek out jobs that offer this amenity. As we discuss in the concluding section, such nonrandom sorting is likely the primary reason why we cannot find evidence of a compensating differential in Table 4.

\section{Conclusions}

Surveys of workers consistently rank health insurance as far and away the most important among all benefits offered in the workplace (Salisbury, 2001). Intuitively, health insurance has the potential to influence numerous labor market decisions and many individuals may be reluctant to consider working for companies that do not provide health benefits. ${ }^{34}$ At the same time, employers are increasingly facing large increases in the costs of providing these benefits. Hence, understanding how the provision of these benefits affects the labor market has substantial policy and human resource implications.

In this paper, we extended the health economics literature on compensating differentials by introducing an empirical approach that allows 1) both individual observed and 
unobserved (to the econometrician) characteristics to be rewarded differently in different sectors of the economy, and 2) selection to operate on both sides of the labor market. An important feature of this model is that the estimates enable us to test several assumptions that are made with existing empirical strategies. We find that the assumption that unobserved attributes are rewarded equally in both sectors which underlies fixed effects and traditional differencing strategies is rejected. In addition, we find evidence that there is substantial selection on unobserved characteristics, which rules out matching and OLS strategies. Finally, we find that selection operates on both sides of the labor market, a feature that cannot be accounted for by traditional control function estimators.

While we do not find any evidence of a health insurance compensating wage differential, we observe that health insurance has increasingly influenced wage inequality. We present evidence that the provision of health insurance is increasingly affecting the dispersion of wages across sectors, which is consistent with the findings in the compensating differentials literature that have explored the incidence question from the perspective of employers. Estimates from our model are also used to decompose the wage gap between the sectors and we find there are substantial changes in the selection of workers to firms that provide health insurance benefits. Specifically, we observe that there has been increasing sorting based on comparative advantage. Finally, we find that recently displaced workers are searching nearly three weeks longer for jobs that provide health benefits and that these workers on average have lower unobserved productivity attributes.

An important limitation of this study is that the impacts we estimate are applicable to displaced workers only. The composition of displaced workers not only differs from other workers in the labor market, but has also changed over time. ${ }^{35}$ Yet, it should be noted that our finding of an increasing role of health insurance on wages is consistent with the recent health economics literature that indicates that the recent rise in health insurance premiums affects a variety of labor market outcomes. ${ }^{36}$ Consequently, it is likely our findings have some limited external validity. 
We do not view our failure to find evidence of a compensating differential despite using a more general estimation approach as a rejection of the underlying theory. The simple compensating differentials theory remains inconsistent with two empirical features of the U.S. labor market. First, there is large variability in costs of health insurance across similar firms. Understanding the sources of this variability may suggest additional variables that may need to be accounted for in wage regressions. In this study, we find strong evidence that the sorting of workers to jobs is consistent with comparative advantage. ${ }^{37}$ While, sorting in the labor market is likely to lead to strong correlations between observed and unobserved attributes of the individual with the corresponding variables of their co-workers, our evidence also indicates that in recent years the distribution of these unobserved attributes is more heterogeneous in the health insurance sector. Thus, sorting to firms on the basis of preferences for health insurance is not perfect and there still may remain heterogeneity at the firm level that is not a function of these individual specific heterogeneities, suggesting that frictions exist in the labor market. Accounting for such heterogeneity in addition to individual heterogeneity as well as the identification of the impacts of endogenous group formation at firms has typically been ignored (in part due to data limitations) in the health insurance compensating differentials literature. ${ }^{38}$

Second, employers cannot set employee specific compensation packages. An increasing body of evidence suggests that there is likely substantial heterogeneity regarding preferences for health insurance benefits among workers within firms. For example, Gruber and Lettau (2004) find that within firms, the median worker and workers in the highest quantiles of salary exhibit a disproportionate amount of influence on decisions related to health insurance coverage. These workers may also be willing to bear a disproportionate amount of the costs through lower wages, and if these tastes can indeed be proxied by observables such as salary, it may be useful to examine whether the tradeoff exists by examining those most likely affected. For example, with longitudinal matched employee and employer data it is possible to examine within firms how the estimated trade-off varies 
across the salary distribution and how the distribution of residual wage dispersion varies across firms that differ in both benefit provision and the cost of benefits. ${ }^{39}$ In conclusion, future research needs to consider general empirical models with richer data sources to determine whether the compensating differential truly exists as well as shed more light on how health insurance provision affects the labor market. 


\section{Notes}

${ }^{1}$ Between 2001 and 2004, premiums for family coverage shot up by 59 percent, compared to a 9.7 percent gain in inflation and a 12.3 percent wage growth rate. See Kaiser Family Foundation and Health Research and Educational Trust (2004) for details.

${ }^{2}$ The Kaiser Family Foundation (2005) reports that only $60 \%$ of companies offered health insurance to their employees in 2005, down from $69 \%$ in 2000 . Gruber and McKnight (2003) report that, in 1982, $44 \%$ of those who were covered by their employerprovided health insurance had their costs fully financed by their employer, but by 1998 this had fallen to $28 \%$. Cutler (2002) finds that the increasing employee costs for health insurance resulted in employees declining coverage in the 1990s. Increased anecdotal evidence suggests that this trade-off exists, and there are reports in the popular press that firms have even made termination decisions based strictly on an individual's health behavior, such as smoking, in an effort to reduce health insurance costs (Armour (2005)).

${ }^{3}$ Bundorf (2002) shows that higher wage workers are more likely to receive health insurance benefits. Gruber and Lettau (2004) find that the decision to offer health insurance at the firm level depends on the prices faced by both the median worker and highly compensated workers. Wiatrowski (1995) reports that medium and large establishments were $20 \%$ more likely to offer health insurance to full time employees relative to small establishments. Dranove, Spier and Baker (2000) show that spousal coverage affects employment decisions.

${ }^{4}$ Currie and Madrian (1999) present a survey of the early cross sectional and longitudinal compensating differential studies in the health economics literature. They conclude that many of these studies did not have the appropriate data to estimate the magnitude of the compensating differential.

${ }^{5}$ Pauly (1986) suggests that the sorting of workers based on these tastes across sectors is imperfect. Changes in the sorting process over time could partially explain the more rapid increases in health insurance costs that may simultaneously affect the levels and 
dispersion of salaries within firms that provide health insurance benefits. We discuss the implications of imperfect sorting for the compensating differentials literature in the final section.

${ }^{6}$ The implications of absolute and comparative advantage as sorting mechanisms are outlined in Willis (1986) and Sattinger (1993).

${ }^{7}$ More generally, worker sorting could have profound impacts on the macroeconomy if non market interactions exist, such as peer effects (e. g. Benabou (1996) and Kremer (1993)).

${ }^{8}$ See Jacobson, LaLonde and Sullivan (1993) for a careful analysis of earnings loss following displacement and Farber (2003) for a survey of research on the experiences of displaced workers.

${ }^{9}$ Blue Cross and Blue Shield of Louisiana estimated that 200,000 residents who had health insurance through the workplace lost their benefits due to Hurricane Katrina.

${ }^{10}$ See Katz and Autor (1999) for an extensive overview of recent changes in the U.S. wage structure.

${ }^{11}$ An explicit characterization that would generate equations (1)-(4) in the context of unions is provided in Robinson (1989). The model considered in this paper is based on and discussed in further detail in Lemieux (1998). As noted by Lemieux (1998), the model rules out individuals who change work voluntarily and focuses on involuntarily job loss.

${ }^{12}$ Most econometric approaches assume constant slope coefficients which rules out comparative advantage.

${ }^{13}$ Cutler (1995) reports that there exists huge variation in health insurance premiums among otherwise identical firms that is partially the result of heterogeneity in the workforce along health dimensions.

${ }^{14}$ Let $\theta_{i}=\theta_{i}^{N}-\zeta$ and $\theta_{i}=\frac{\theta_{i-\zeta}^{H}}{\varphi}$ where $\zeta$ is an orthogonal error component as in Lemieux (1998).

${ }^{15}$ Note that if one sets the $\Psi=1$, this is equivalent to a first differenced estimation 
procedure and imposes the assumption that unobserved attributes are rewarded in exactly the same manner in both sectors. This assumption of constant rewards to unobserved attributes also underlies fixed effects strategies. Note NLLS estimates of $\Psi$ would be biased even if the residuals are not serially correlated

${ }^{16}$ Note as we discuss in the subsequent section our results do not change if we include individual's own union status pre and post displacement in the estimating equation. The state level aggregates are also likely to be correlated with any firm level residual.

${ }^{17}$ The estimates of $\beta^{H I}, \beta^{H}, \beta^{N}$ and $\psi$ are obtained from equation (10) and summary statistics provide information on $\bar{x}_{H}=E\left[x_{i t} \mid H I_{i t}=1\right]$ and $\bar{x}_{N}=E\left[x_{i t} \mid H I_{i t}=0\right]$. Similarly, $\bar{\theta}_{H}=E\left[\theta_{i} \mid H I_{i t}=1\right]$ and $\bar{\theta}_{N}=E\left[\theta_{i} \mid H I_{i t}=0\right]$ where $\theta_{i}$ is calculated using the predicted regressors via equation (9). The gap in the variance of wages can also be decomposed using the same information, and considering that $\Sigma_{X H}=\operatorname{Var}\left[x_{i t} \mid H I_{i t}=\right.$ $1], \Sigma_{X N}=\operatorname{Var}\left[x_{i t} \mid H I_{i t}=0\right], \sigma_{\theta H}^{2}=\operatorname{Var}\left[\theta_{i} \mid H I_{i t}=1\right], \sigma_{\theta N}^{2}=\operatorname{Var}\left[\theta_{i} \mid H I_{i t}=0\right]$, $\Sigma_{X \theta_{H}}=\operatorname{Cov}\left[x_{i t}, \theta_{i} \mid H I_{i t}=1\right], \Sigma_{X \theta_{N}}=\operatorname{Cov}\left[x_{i t}, \theta_{i} \mid H I_{i t}=0\right], \sigma_{H}^{2}=\operatorname{Var}\left[\epsilon_{i t} \mid H I_{i t}=1\right]$, and $\sigma_{N}^{2}=\operatorname{Var}\left[\epsilon_{i t} \mid H I_{i t}=0\right]$.

${ }^{18}$ Hammermesh (1987) presents evidence from early DWS surveys that these displacements indeed come as a surprise to the worker and firm.

${ }^{19}$ The DWS does not contain hourly wage rates and we had to calculate this variable. We assumed that health insurance is obtained from an individual's primary position and calculated the hourly wage rate for this position using information in the DWS. Specifically, we took the difference between total wages and earnings from other jobs and divided that by the average hours worked per week *weeks worked in a year.

${ }^{20}$ Simon (2001) used data from 1984 to 2000 in her analysis. The CPS 2004 data differ in their industry and occupation codes, which makes their addition to the analysis impossible, since we use the average unionization rate in the industry as instrument. Besides from the fact that we include an additional wave, the CPS 2002, our final sample differs slightly from that in Simon (2001) as we apply a stricter definition of full time 
work at the previous job. Note that the differences in the sample do not affect any of the conclusions in Simon (2001).

${ }^{21}$ In all waves of the survey, the health insurance information about the old job refers to health insurance from the worker's own employer. From 1984 to 1992, the new job health insurance variable asked for whether any group health insurance was held, and from 1994 onwards asked whether any private health insurance was held at the present time.

${ }^{22}$ Approximately $6 \%$ of matched individuals privately purchased insurance and nearly $31 \%$ received health insurance from a spouse. This subsample was removed from the analysis. Note, our qualitative and quantitative results were robust if this subsample were included in the estimation sample. This should reduce concerns regarding our implicit assumption that for those individuals who could not be matched with the March CPS, health insurance reported in the DWS was obtained from the primary employer.

${ }^{23}$ Health care reform was a major component of Bill Clinton's campaign in 1992. This year also saw a marked slowdown in medical spending and the end to a period of rapid growth in enrollment in managed care plan. While $5 \%$ of the privately insured were in managed care in 1980 it had risen to approximately $75 \%$ in 1992 and that percentage has been fairly stable since 1992 .

${ }^{24}$ More generally, there is substantial heterogeneity in unemployment spans and post displacement job outcomes for displaced workers. Seitchik (1991) reports that while approximately $\frac{1}{3}$ of all displaced workers were reemployed within 5 weeks, about $\frac{1}{3}$ were not reemployed until after more than 6 months. He also reports that $43 \%$ of workers displaced between 1981 and 1986 had higher earnings on reemployed jobs in 1986 whereas over 30\% of workers were earning less than $\frac{3}{4}$ of their former wages.

${ }^{25}$ The difference in the tax treatment of wage and non-wage compensation also means that highly compensated workers will equally be those who most value non-wage compensation.

${ }^{26}$ For example, Pauly and Herring (1999) report lower returns to experience in firms 
that provide health insurance benefits, whereas Olson (2002) reports that being married reduced wages for women working full time with health insurance.

${ }^{27}$ In fact, the OLS estimate of the impact of health insurance in a simple wage equation does exceed the true effect of health insurance on wages presented in Table 3. Note, the OLS estimate may also suffer from bias if there are correlations between observed and unobserved attributes.

${ }^{28}$ Recall this is the gap in the variance of log hourly wages. This gap is small relative to the gap in average log hourly wages.

${ }^{29}$ As a robustness check we explored four alternative instrument sets. These sets were chosen based on a suggestion in Lemieux (1998) to exploit the strict exogeneity condition on the regressors of the model and use higher order terms and interaction terms of the explanatory variables as instruments. While some of the instrument sets had slightly better first stage properties the general pattern of our results (available from the authors) were robust to the different instrument sets. Note, the selection of these instrument sets relies on the plausibility of the strict exogeneity condition for identification.

${ }^{30}$ The inconsistency of the GMM estimates depends on the relevance of the instrumental variable. Hahn and Hausman (2003) show that the finite sample bias of these estimates is inversely related to the first stage F-statistic.

${ }^{31}$ Note that the inclusion of individual union status reduces efficiency as we use a smaller sample and may also lead to additional concerns regarding endogeneity. Also note that our underlying model has individuals choosing between sectors that differ only in their health insurance provision and not union status.

${ }^{32}$ Note that $\theta_{i s}$ is measured with error since $\xi_{i s}$ is included on the right hand side of equation (9). Since the model assumes that $\eta_{i s}$ in equation (3) is distributed iid over time, this regression intuitively corresponds to regressing two variables with classical measurement error on each other and obtaining the true signal by calculating the predicted outcome $\left(\widehat{\theta}_{i}\right)$. 
${ }^{33}$ We investigated the sensitivity of our results to the definition of $t_{2}$. We found that for workers above 45 the estimates of $\gamma_{3}$ increase in absolute value as $t_{2}$ indicates later time periods (i.e. 1998 onwards).

${ }^{34}$ Madrian (1994) finds that among married men with pregnant wives, those without health insurance are twice as likely to switch jobs.

${ }^{35}$ Farber (2001) describes how the characteristics of displaced workers have changed over time.

${ }^{36}$ For example, Cutler and Madrian (1998) and Baicker and Chandra (2006) find impacts on hours worked and employment rates whereas Gruber and Krueger (1991) using similar identification strategies with data from earlier time periods find no impacts.

${ }^{37}$ There is, indeed, some evidence of worker sorting in the context of health insurance within the health economics literature. Several studies (Marquis and Long (1995), Monheit and Vistnes (1999) and Levy (1998)) show that workers with low preferences for health insurance are disproportionately employed in firms that do not offer coverage. Similarly evidence of employees sorting to firms based on health insurance benefits is shown in Scott, Berger and Black (1989), Dranove, Spier and Baker (2000), and Levy (1998). Yet, the evidence also indicates that sorting of workers to firms on the basis of preferences for the compensation package is imperfect.

${ }^{38}$ Since the individual unobserved attributes of wokers that sort into a firm are likely to be similar, a negative within group correlation between observed and unobserved characteristics of individuals will arise, even if these variables are uncorrelated in the population. Using a general model to estimate hedonic equations, Epple (1987) demonstrates that simply using group fixed effects is unlikely to be sufficient to overcome potential biases.

${ }^{39}$ Alternatively one could examine the tradeoff over the age or tenure distribution within firms. For example, one could hypothesize that consistent with the findings in Pauly and Herring (1999), workers with high tenure may have lower labor market mobility and be more willing to accept increased shares of health insurance costs over time. 


\section{References}

[1] Armour, S., 2005. Trend, You smoke? You're fired!. USA Today. http,//www.usatoday.com/money/companies/management/2005-05-11-smokeusat_x.htm.

[2] Baicker, K. and Chandra A. 2006. The Labor Market Effects of Rising Health Insurance Premiums. Journal of Labor Economics 24, 609-634.

[3] Benabou, R., 1996. Heterogeneity, Stratification, and Growth, Macroeconomic Implications of Community Structure and School Finance. American Economic Review $86,584-609$.

[4] Buchmueller, T. C., DiNardo, J., Valletta, R. G., 2002. Union Effects on Health Insurance Provision and Coverage in the United States. Industrial and Labor Relations Review 55, 610-627.

[5] Bundorf, K. M., 2002. Employee Demand for Health Insurance and Employer Health Plan Choices. Journal of Health Economics 21, 65-88.

[6] Currie, J., Madrian, B., 1999. "Health, Health Insurance and the Labor Market in D. Card and O. Ashenfelter (eds), Handbook of Labor Economics 3C, 3309-3407.

[7] Cutler, D. M., 2002. Employee Costs and the Decline in Health Care Coverage. NBER Working Paper No. 9036.

[8] Cutler, D. M. and Madrian, B. 1998. Labor Market Responses to Rising Health Insurance Costs: Evidence on Hours Worked. RAND Journal of Economics 29, 50930 .

[9] Cutler, D. M., 1995. The Incidence of Adverse Medical Outcomes Under Prospective Payment. Econometrica 63, 29-50.

[10] Dranove, D., Spier, K. E., Baker, L., 2000. Competition Among Employers Offering Health Insurance. Journal of Health Economics 19, 121-140.

[11] Employee Benefit Research Institute, 2002. Databook on Employee Benefits. 4th ed. http,//www.ebri.org/publications/books/index.cfm?fa=databook

[12] Epple, D. 1987. Hedonic Prices and Implicit Markets: Estimating Demand and Supply Functions for Differentiated Products. Journal of Political Economy 95, 59-80.

[13] Farber, H. S., 2003. Job Loss in the United States, 1981-2001. NBER Working Paper No. $970 \%$. 
[14] Farber, H. S., Levy, H., 2000. Recent Trends in Employer-Sponsored Health Insurance, Are Bad Jobs Getting Worse?. Journal of Health Economics 19, 93-119.

[15] Gruber, J., Lettau, M., 2004. How Elastic is the Firm's Demand for Health Insurance. Journal of Public Economics 88, 1273-1293.

[16] Gruber, J., McKnight, R., 2003. Why Did Employee Health Insurance Contributions Rise?. Journal of Health Economics 22, 1085-1104.

[17] Gruber, J., 1994. The Incidence of Mandated Maternity Benefits. American Economic Review 84, 622-641.

[18] Gruber, J., and Krueger, A. B., 1991. The incidence of mandated employer-provided insurance: Lessons from workers' compensation insurance. Tax Policy and the Economy 5:111-43.

[19] Hahn, J., Hausman, J. 2003. Instrumental Variable Estimation with Valid and Invalid Instruments., MIT Department of Economics Working Paper No. 03-26.

[20] Hamermesh, D. S. 1987. The Costs of Worker Displacement. Quarterly Journal of Economics 102, 51-75.

[21] Jacobson, L., LaLonde, R., Sullivan, D., 1993. Earnings Losses of Displaced Workers. American Economic Review 83, 685-709.

[22] Kaiser Family Foundation and Health Research and Educational Trust, 2005. Employer Health Benefits Survey. www.kff.org.

[23] Kaiser Family Foundation and Health Research and Educational Trust, 2004. Employer Health Benefits Survey. www.kff.org.

[24] Katz L. F., Autor, D. H. 1999. Changes in the Wage Structure and Earnings Inequality, in O. Ashenfelter and D. Card, eds., Handbook of Labor Economics 3A, 1463-1555.

[25] Kremer, M., 1993. The O-Ring Theory of Economic Development. Quarterly Journal of Economics 108, 551-576.

[26] Lemieux, T., 1998. Estimating the Effects of Unions on Wage Inequality in a Panel Data Model with Comparative Advantage and Nonrandom Selection. Journal of Labor Economics 16, 261-291.

[27] Levy, H., 1998. Who Pays for Health Insurance? Employee Contributions to Health Insurance Premiums. Princeton University Industrial Relations Section Working Paper 398. 
[28] Madrian, B. C., 1994. Employment-Based Health Insurance and Job Mobility: Is There Evidence of Job-Lock? Quarterly Journal of Economics 109, 27-54.

[29] Marquis, M. S., Long, S. H., 1995. Worker Demand for Health Insurance in the Non-Group Market. Journal of Health Economics 14, 47-63.

[30] Monheit, A. C., Vistnes, J.C., 1999. Health Insurance Availability at the Workplace, How Important are Workers Preferences. Journal of Human Resources 34, 770-785.

[31] Moreira, Marcelo. 2003. A conditional likelihood ratio test for structural models. Econometrica 71, no. 4:1027-48.

[32] Olson, C. A., 2002. Do Workers Accept Lower Wages in Exchange for Health Benefits. Journal of Labor Economics 20, S91-S114.

[33] Oyer, P., 2004. Recall Bias Among Displaced Workers. Economics Letters 82, 392397.

[34] Pauly, M. V., 2001. Making Sense of a Complex System, Empirical Studies of Employment-Based Health Insurance. International Journal of Health Care Finance and Economics 1, 333-339.

[35] Pauly, M., Herring, B., 1999. Pooling Health Insurance Risks. American Enterprise Institute Press, Washington, DC.

[36] Pauly, M. V. 1986. Taxation, Health Insurance, and Market Failure in the Medical Economy. Journal of Economic Literature 24, 629-675.

[37] Robinson, C., 1989. The Joint Determination of Union Status and Union Wage Effects, Some Tests of Alternative Models. Journal of Political Economy 97, 639-67.

[38] Salisbury, D. L. 2001. EBRI Research Highlights: Retirement and Health Data Employee Benefit Research Institute (EBRI) EBRI Special Report SR-36, and EBRI Issue Brief No. 229.

[39] Sattinger, M, 1993. Assignment Models of the Distribution of Earnings. Journal of Economic Literature 31 831-880.

[40] Scott, F., Berger, M. C., Black, D., 1989. Effects of the Tax Treatment of Fringe Benefits on Labor Market Segmentation. Industrial and Labor Relations Review 42, $216-229$.

[41] Seitchik, A. 1991. Who Are Displaced Workers? in J. T. Addison, ed., Job 51 Displacement: Consequences and Implications for Policy. Detroit: Wayne State University Press. 
[42] Sheiner L. (1999), "Health Care Costs, Wages and Aging," Federal Reserve Board of Governors \#99-19, Washington D. C.

[43] Simon, K., 2001. Involuntary Job Change and Employer Provided Health Insurance; Evidence of a Wage/Fringe Benefit Tradeoff?. International Journal of Health Care Finance and Economics 1, 249-271.

[44] Staiger, D., Stock, J.H., 1997. Instrumental Variables Regression with Weak Instruments. Econometrica 65, 557-586.

[45] Wiatrowski, W. J., 1995. Who Really Has Access to Employer-Provided Health Benefits?. Monthly Labor Review 118, 36-44.

[46] Willis, R. J. 1986. Wage Determinants: A Survey and Reinterpretation of Human Capital Earnings Functions. in O Ashenfelter and R Layard (eds), Handbook of Labor Economics 1, 525-602. 
Table 1: Descriptive Statistics

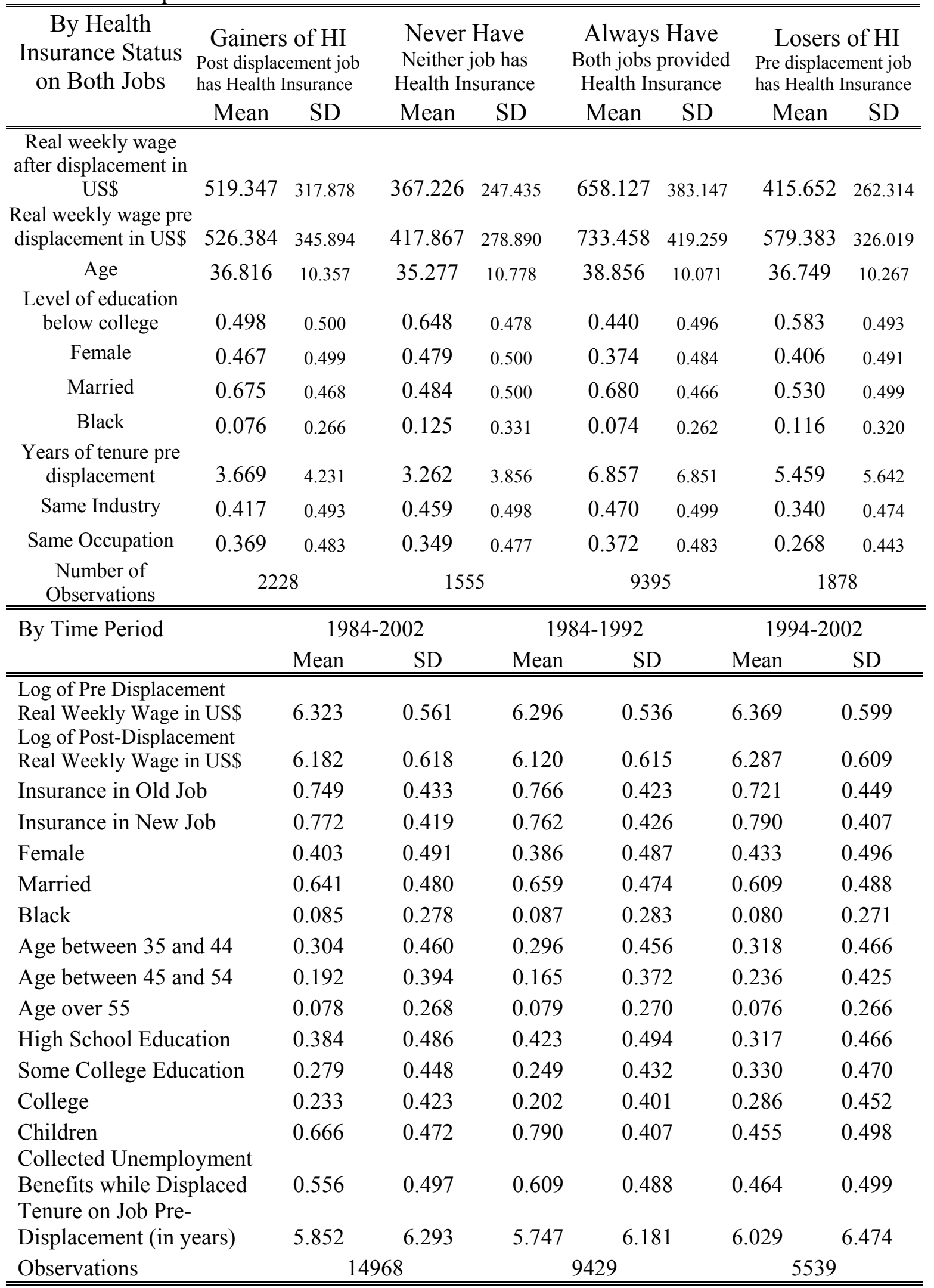


Table 2: GMM Estimates of the Wage Equation

\begin{tabular}{|c|c|c|c|}
\hline & 1984-2002 & 1984-1992 & 1994-2002 \\
\hline Health Insurance & $\begin{array}{c}0.046 \\
(0.054)\end{array}$ & $\begin{array}{c}0.054 \\
(0.064)\end{array}$ & $\begin{array}{l}-0.021 \\
(0.093)\end{array}$ \\
\hline $\begin{array}{l}\text { Point estimates of the differential returns to unobserved } \\
\text { skills between insured and uninsured workers }(\psi)\end{array}$ & $\begin{array}{l}0.788^{\mathrm{a}} \\
(0.041)\end{array}$ & $\begin{array}{c}0.892^{\mathrm{a}} \\
(0.053)\end{array}$ & $\begin{array}{c}0.790^{\mathrm{a}} \\
(0.060)\end{array}$ \\
\hline (1) & $\begin{array}{l}-0.062^{\mathrm{a}} \\
(0.007)\end{array}$ & $\begin{array}{l}-0.071^{\mathrm{a}} \\
(0.009)\end{array}$ & $\begin{array}{l}-0.052^{a} \\
(0.012)\end{array}$ \\
\hline Married & $\begin{array}{l}0.035^{\mathrm{a}} \\
(0.008)\end{array}$ & $\begin{array}{l}0.039^{\mathrm{a}} \\
(0.011)\end{array}$ & $\begin{array}{c}0.011 \\
(0.013)\end{array}$ \\
\hline Black & $\begin{array}{l}-0.039^{a} \\
(0.012)\end{array}$ & $\begin{array}{l}-0.025^{\mathrm{c}} \\
(0.014)\end{array}$ & $\begin{array}{l}-0.079^{a} \\
(0.021)\end{array}$ \\
\hline Age between 35 and 44 & $\begin{array}{l}0.020^{\mathrm{a}} \\
(0.008)\end{array}$ & $\begin{array}{l}0.015 \\
(0.010)\end{array}$ & $\begin{array}{c}0.003 \\
(0.014)\end{array}$ \\
\hline Age between 45 and 54 & $\begin{array}{l}-0.003 \\
(0.010)\end{array}$ & $\begin{array}{l}-0.027^{b} \\
(0.012)\end{array}$ & $\begin{array}{c}0.009 \\
(0.016)\end{array}$ \\
\hline Over 55 years old & $\begin{array}{l}-0.065^{\mathrm{a}} \\
(0.014)\end{array}$ & $\begin{array}{l}-0.091^{\mathrm{a}} \\
(0.017)\end{array}$ & $\begin{array}{l}-0.017 \\
(0.025)\end{array}$ \\
\hline High School Graduate & $\begin{array}{c}0.086^{\mathrm{a}} \\
(0.011)\end{array}$ & $\begin{array}{c}0.068^{\mathrm{a}} \\
(0.013)\end{array}$ & $\begin{array}{c}0.105^{\mathrm{a}} \\
(0.022)\end{array}$ \\
\hline Some College & $\begin{array}{c}0.133^{\mathrm{a}} \\
(0.012)\end{array}$ & $\begin{array}{c}0.100^{\mathrm{a}} \\
(0.014)\end{array}$ & $\begin{array}{c}0.149^{\mathrm{a}} \\
(0.022)\end{array}$ \\
\hline College Degree and above & $\begin{array}{c}0.196^{\mathrm{a}} \\
(0.013)\end{array}$ & $\begin{array}{c}0.172^{a} \\
(0.015)\end{array}$ & $\begin{array}{c}0.211^{\mathrm{a}} \\
(0.023)\end{array}$ \\
\hline Number of children & $\begin{array}{l}-0.030^{a} \\
(0.008)\end{array}$ & $\begin{array}{l}-0.029^{b} \\
(0.013)\end{array}$ & $\begin{array}{c}0.015 \\
(0.013)\end{array}$ \\
\hline Pre Displacement Tenure & $\begin{array}{c}0.040^{\mathrm{a}} \\
(0.004)\end{array}$ & $\begin{array}{c}0.046^{a} \\
(0.005)\end{array}$ & $\begin{array}{c}0.030^{\mathrm{a}} \\
(0.007)\end{array}$ \\
\hline Pre Displacement Tenure Squared & $\begin{array}{l}-0.001^{\mathrm{a}} \\
(0.000)\end{array}$ & $\begin{array}{l}-0.001^{\mathrm{a}} \\
(0.000)\end{array}$ & $\begin{array}{l}-0.001^{b} \\
(0.000)\end{array}$ \\
\hline Female*health insurance & $\begin{array}{l}-0.171^{\mathrm{a}} \\
(0.010)\end{array}$ & $\begin{array}{l}-0.177^{\mathrm{a}} \\
(0.012)\end{array}$ & $\begin{array}{l}-0.153^{\mathrm{a}} \\
(0.016)\end{array}$ \\
\hline Married*health insurance & $\begin{array}{c}0.042^{\mathrm{a}} \\
(0.011)\end{array}$ & $\begin{array}{c}0.052^{\mathrm{a}} \\
(0.015)\end{array}$ & $\begin{array}{c}0.044^{\mathrm{a}} \\
(0.017)\end{array}$ \\
\hline Black*health insurance & $\begin{array}{l}-0.054^{\mathrm{a}} \\
(0.016)\end{array}$ & $\begin{array}{l}-0.072^{\mathrm{a}} \\
(0.019)\end{array}$ & $\begin{array}{c}0.003 \\
(0.028)\end{array}$ \\
\hline (Age between 35 and 44 )*health insurance & $\begin{array}{c}0.096^{\mathrm{a}} \\
(0.011)\end{array}$ & $\begin{array}{c}0.088^{a} \\
(0.014)\end{array}$ & $\begin{array}{c}0.124^{a} \\
(0.019)\end{array}$ \\
\hline (Age between 45 and 54 )*health insurance & $\begin{array}{c}0.127^{\mathrm{a}} \\
(0.013)\end{array}$ & $\begin{array}{c}0.132^{a} \\
(0.018)\end{array}$ & $\begin{array}{c}0.134^{\mathrm{a}} \\
(0.022)\end{array}$ \\
\hline (Over 55 years old)*health insurance & $\begin{array}{c}0.120^{a} \\
(0.019)\end{array}$ & $\begin{array}{c}0.119^{a} \\
(0.023)\end{array}$ & $\begin{array}{c}0.141^{\mathrm{a}} \\
(0.033)\end{array}$ \\
\hline High School Graduate*health insurance & $\begin{array}{c}0.094^{a} \\
(0.015)\end{array}$ & $\begin{array}{c}0.094^{\mathrm{a}} \\
(0.018)\end{array}$ & $\begin{array}{c}0.114^{\mathrm{a}} \\
(0.032)\end{array}$ \\
\hline Some College*health insurance & $\begin{array}{c}0.177^{\mathrm{a}} \\
(0.016)\end{array}$ & $\begin{array}{c}0.176^{\mathrm{a}} \\
(0.020)\end{array}$ & $\begin{array}{c}0.207^{\mathrm{a}} \\
(0.032)\end{array}$ \\
\hline College*health insurance & $\begin{array}{c}0.422^{\mathrm{a}} \\
(0.017)\end{array}$ & $\begin{array}{c}0.366^{\mathrm{a}} \\
(0.021)\end{array}$ & $\begin{array}{c}0.505^{\mathrm{a}} \\
(0.035)\end{array}$ \\
\hline Number of children*health insurance & $\begin{array}{l}-0.007 \\
(0.011)\end{array}$ & $\begin{array}{l}-0.042^{b} \\
(0.018)\end{array}$ & $\begin{array}{c}0.016 \\
(0.017)\end{array}$ \\
\hline Pre Displacement Tenure* health insurance & $\begin{array}{l}-0.023^{\mathrm{a}} \\
(0.004)\end{array}$ & $\begin{array}{l}-0.033^{\mathrm{a}} \\
(0.005)\end{array}$ & $\begin{array}{c}-0.007 \\
(0.007)\end{array}$ \\
\hline Pre Displacement Tenure Squared* health insurance & $\begin{array}{c}0.001^{\mathrm{a}} \\
(0.000)\end{array}$ & $\begin{array}{c}0.001^{\mathrm{a}} \\
(0.000)\end{array}$ & $\begin{array}{c}0.000 \\
(0.000)\end{array}$ \\
\hline Observations & 14908 & 9387 & 5521 \\
\hline
\end{tabular}

Note: Regressions also include indicators on employer industry and region of residence and their interactions with health insurance. Standard errors in parentheses, ${ }^{\mathrm{a}},{ }^{\mathrm{b}}$ and ${ }^{\mathrm{c}}$ denote statistically different from zero at the $1 \%, 5 \%$ and $10 \%$ confidence levels, respectively. 
Effect of health insurance on workers in health insurance sector:

1. Compensating Wage Differential, $\beta^{H I}$

2. Effect of observed skills, $\bar{x}_{H}^{\prime}\left(\beta^{H}-\beta^{N}\right)$

3. Effect of unobserved skills, $(\psi-1) \bar{\theta}_{H}$ Total effect

Selection bias:

4. Differences in observed skills, $\left(\bar{x}_{H}^{\prime}-\bar{x}_{N}^{\prime}\right) \beta^{N}$

5. Differences in unobserved skills, $\left(\bar{\theta}_{H}-\bar{\theta}_{N}\right)$ Total bias

Unadjusted wage gap (WG)
0.046

0.054

$-0.021$

0.203

0.156

0.318

$\underline{0.008}$

$\underline{0.000}$

$\underline{0.015}$

0.257

0.210

0.312

0.112

0.132

0.089

$\underline{0.035}$

0.047

$\underline{0.038}$

$\underline{0.147}$

0.404 $\underline{0.179}$

0.389

Note: The decomposition is based on equation (6) and we use the estimates presented in Table 2 to construct each component. 
Effect of health insurance on workers in health insurance sector:

1. Effect of observed skills, $\beta^{H^{\prime} \Sigma_{X H}} \beta^{H}-\beta^{N^{\prime}} \Sigma_{X N} \beta^{N}$

2. Effect of unobserved skills, $\left(\psi^{2}-1\right) \sigma_{\theta_{H}}^{2}$

0.058

0.043

0.074

3. Covariance term, $2\left(\psi \beta^{H}-\beta^{N}\right) \Sigma_{X \theta H}$

$-0.119-0.047$

$-0.129$

Total effect

$\underline{0.004} \quad \underline{0.005} \quad \underline{0.006}$

$\begin{array}{lll}-0.056 & 0.002 & -0.049\end{array}$

Selection bias:

4. Differences in observed skills, $\beta^{N^{\prime}}\left(\Sigma_{X H}-\Sigma_{X N}\right) \beta^{N}$

5. Differences in unobserved skills, $\sigma_{\theta H}^{2}-\sigma_{\theta N}^{2}$

0.001

0.002

0.000

6. Covariance term, $2 \beta^{N^{\prime}}\left(\Sigma_{X \theta H}-\Sigma_{X \theta N}\right)$

0.065

0.000

0.064

Total bias

$-0.02$

$\underline{-0.015}$

$\underline{-0.024}$

0.044

$-0.014$

0.039

Difference in residual variance, $\sigma_{H}^{2}-\sigma_{N}^{2}$

$-0.001$

$-0.002$

0.000

Unadjusted variance gap (WG)

$-0.013$

$-0.014$

$-0.009$

Note: The decomposition is based on equation (7) and we use the estimates presented in Table 2 to construct each component. 
Table 5: First Stage Regressions of Pre Displacement Wage Assuming $\psi=1$

\begin{tabular}{|c|c|c|c|}
\hline Time Period & 1984-2002 & 1984-1992 & 1994-2002 \\
\hline "Unionization Rate in Pre-Displacement & $1.27 * 10 \mathrm{E}-3^{\mathrm{a}}$ & $2.32 * 10 \mathrm{E}-3^{\mathrm{a}}$ & $-1.62 * 10 \mathrm{E}-3^{\mathrm{a}}$ \\
\hline Industry & $(3.0 * 10 \mathrm{E}-4)$ & $(3.5 * 10 \mathrm{E}-4)$ & $(6.6 * 10 \mathrm{E}-4)$ \\
\hline Health Insurance Pre Displacement & $\begin{array}{l}0.236^{\mathrm{a}} \\
(0.035)\end{array}$ & $\begin{array}{c}0.230^{\mathrm{a}} \\
(0.044)\end{array}$ & $\begin{array}{c}0.160^{\mathrm{a}} \\
(0.062)\end{array}$ \\
\hline Married & $\begin{array}{c}0.061^{\mathrm{a}} \\
(0.022)\end{array}$ & $\begin{array}{c}0.088^{\mathrm{a}} \\
(0.028)\end{array}$ & $\begin{array}{c}0.054 \\
(0.037)\end{array}$ \\
\hline Black & $\begin{array}{l}-0.037 \\
(0.027)\end{array}$ & $\begin{array}{l}-0.087^{\mathrm{a}} \\
(0.033)\end{array}$ & $\begin{array}{c}0.069 \\
(0.049)\end{array}$ \\
\hline Age between 35 and 44 & $\begin{array}{c}0.067^{\mathrm{a}} \\
(0.022)\end{array}$ & $\begin{array}{c}0.072^{\mathrm{a}} \\
(0.028)\end{array}$ & $\begin{array}{l}0.066^{\mathrm{C}} \\
(0.039)\end{array}$ \\
\hline Age between 45 and 54 & $\begin{array}{l}0.105^{\mathrm{a}} \\
(0.031)\end{array}$ & $\begin{array}{c}0.113^{\mathrm{a}} \\
(0.038)\end{array}$ & $\begin{array}{l}0.122^{\mathrm{b}} \\
(0.053)\end{array}$ \\
\hline Over 55 years old & $\begin{array}{c}0.045 \\
(0.045)\end{array}$ & $\begin{array}{c}0.028 \\
(0.053)\end{array}$ & $\begin{array}{c}0.080 \\
(0.079)\end{array}$ \\
\hline High School Graduate & $\begin{array}{l}0.134^{\mathrm{a}} \\
(0.023)\end{array}$ & $\begin{array}{l}0.118^{\mathrm{a}} \\
(0.029)\end{array}$ & $\begin{array}{l}0.154^{\mathrm{a}} \\
(0.043)\end{array}$ \\
\hline Some College & $\begin{array}{l}0.252^{\mathrm{a}} \\
(0.027)\end{array}$ & $\begin{array}{c}0.241^{\mathrm{a}} \\
(0.035)\end{array}$ & $\begin{array}{l}0.281^{\mathrm{a}} \\
(0.041)\end{array}$ \\
\hline College Degree and above & $\begin{array}{c}0.447^{\mathrm{a}} \\
(0.035)\end{array}$ & $\begin{array}{c}0.387^{\mathrm{a}} \\
(0.045)\end{array}$ & $\begin{array}{c}0.537^{\mathrm{a}} \\
(0.056)\end{array}$ \\
\hline Pre Displacement Tenure & $\begin{array}{c}0.028^{\mathrm{a}} \\
(0.005)\end{array}$ & $\begin{array}{c}0.030^{\mathrm{a}} \\
(0.006)\end{array}$ & $\begin{array}{c}0.022^{\mathrm{b}} \\
(0.009)\end{array}$ \\
\hline Pre Displacement Tenure Squared & $\begin{array}{l}-7.4 * 10 \mathrm{E}-4^{\mathrm{a}} \\
(2.0 * 10 \mathrm{E}-4)\end{array}$ & $\begin{array}{l}-8.8 * 10 \mathrm{E}-4^{\mathrm{a}} \\
\left(2.2^{*} 10 \mathrm{E}-4\right)\end{array}$ & $\begin{array}{l}-4.2 * 10 \mathrm{E}-4 \\
(4.3 * 10 \mathrm{E}-4)\end{array}$ \\
\hline Married* health insurance & $\begin{array}{c}0.030 \\
(0.021)\end{array}$ & $\begin{array}{c}0.017 \\
(0.029)\end{array}$ & $\begin{array}{c}0.024 \\
(0.035)\end{array}$ \\
\hline Black* health insurance & $\begin{array}{l}-0.011 \\
(0.029)\end{array}$ & $\begin{array}{l}-0.018 \\
(0.035)\end{array}$ & $\begin{array}{c}0.042 \\
(0.052)\end{array}$ \\
\hline (Age between 35 and 44 )* health insurance & $\begin{array}{c}0.018 \\
(0.022)\end{array}$ & $\begin{array}{l}-0.006 \\
(0.027)\end{array}$ & $\begin{array}{l}0.062^{c} \\
(0.038)\end{array}$ \\
\hline (Age between 45 and 54 )* health insurance & $\begin{array}{c}0.018 \\
(0.028)\end{array}$ & $\begin{array}{l}-0.041 \\
(0.036)\end{array}$ & $\begin{array}{l}0.102^{b} \\
(0.044)\end{array}$ \\
\hline$(\text { Over } 55 \text { years old })^{*}$ health insurance & $\begin{array}{l}-0.019 \\
(0.040)\end{array}$ & $\begin{array}{l}-0.037 \\
(0.049)\end{array}$ & $\begin{array}{c}0.053 \\
(0.068)\end{array}$ \\
\hline High School Graduate* health insurance & $\begin{array}{c}0.003 \\
(0.026)\end{array}$ & $\begin{array}{c}0.003 \\
(0.031)\end{array}$ & $\begin{array}{c}0.045 \\
(0.051)\end{array}$ \\
\hline Some College* health insurance & $\begin{array}{l}-0.026 \\
(0.029)\end{array}$ & $\begin{array}{l}-0.043 \\
(0.037)\end{array}$ & $\begin{array}{c}0.020 \\
(0.051)\end{array}$ \\
\hline College degree* health insurance & $\begin{array}{c}0.048 \\
(0.033)\end{array}$ & $\begin{array}{c}0.051 \\
(0.042)\end{array}$ & $\begin{array}{l}0.095^{\mathrm{c}} \\
(0.058)\end{array}$ \\
\hline Pre Displacement Tenure* health insurance & $\begin{array}{l}-0.006 \\
(0.005)\end{array}$ & $\begin{array}{l}-0.011^{\mathrm{c}} \\
(0.006)\end{array}$ & $\begin{array}{c}2.1 * 10 \mathrm{E}-3 \\
(0.010)\end{array}$ \\
\hline $\begin{array}{l}\text { Pre Displacement Tenure Squared* health } \\
\text { insurance }\end{array}$ & $\begin{array}{l}2.6 * 10 \mathrm{E}-4 \\
(2.1 * 10 \mathrm{E}-4)\end{array}$ & $\begin{array}{l}4.6 * 10 \mathrm{E}-4^{\mathrm{b}} \\
\left(2.3^{*} 10 \mathrm{E}-4\right)\end{array}$ & $\begin{array}{l}-1.32 * 10 \mathrm{E}-4 \\
(4.5 * 10 \mathrm{E}-4)\end{array}$ \\
\hline Constant & $\begin{array}{l}5.678^{\mathrm{a}} \\
(0.045)\end{array}$ & $\begin{array}{l}5.816^{\mathrm{a}} \\
(0.060)\end{array}$ & $\begin{array}{l}5.755^{\mathrm{a}} \\
(0.072)\end{array}$ \\
\hline Observations & 14908 & 9387 & 5521 \\
\hline R-Squared & 0.378 & 0.374 & 0.400 \\
\hline First Stage F- statistic on the Instrument & 16.06 & 39.84 & 6.09 \\
\hline
\end{tabular}

Note: Regressions include information on gender, Hispanic, family composition, employer industry, unemployment insurance use, region of residence indicators and their interactions with health insurance. Robust standard errors in parentheses and ${ }^{\mathrm{a}},{ }^{\mathrm{b}}$ and ${ }^{\mathrm{c}}$ denote statistically different from zero at the $1 \%, 5 \%$ and $10 \%$ confidence levels, respectively. 
Table 6: Linear Difference in Difference Estimates of the Impact of Health Insurance Receipt Post 1994 on Job Search Activity Following Displacement

Sample

Health No Health
Insurance Pre Insurance Pre Displacement Displacement

Health Insurance $\left(\gamma_{2}\right)$

Post $1994\left(\gamma_{3}\right)$

Health Insurance * Post $1994\left(\gamma_{4}\right)$

Married

Black

Age between 35 and 44

Age between 45 and 54

Over 55 years old

High School Graduate

Some College

College Degree and Above

Pre Displacement Tenure

Pre Displacement Tenure Squared

Constant

Observations

Adjusted R-Squared $-5.480^{\mathrm{a}}$

$(0.803)$

$-9.346^{\mathrm{a}}$

(1.216)

$2.761^{\mathrm{b}}$

(1.282)

$-0.112$

$(0.450)$

$-0.071$

$(0.565)$

$4.589^{\mathrm{a}}$

(0.907)

$1.050^{\mathrm{b}}$

$(0.515)$

$2.520^{\mathrm{a}}$

(0.644)

$4.734^{\mathrm{a}}$

(0.963)

$-6.068^{\mathrm{a}}$

$(0.958)$

$-7.233^{\mathrm{a}}$

$(0.957)$

$0.480^{\mathrm{a}}$

$(0.095)$

$-0.012^{\mathrm{a}}$

(0.003)

$23.112^{\mathrm{a}}$

(1.242)

10037

0.065
0.393

(0.925)

$-5.284^{\mathrm{a}}$

(1.045)

$-1.981$

(1.347)

$1.362^{\mathrm{b}}$

$(0.689)$

0.024

(0.820)

$4.291^{\mathrm{a}}$

(1.466)

$1.490^{\mathrm{c}}$

$(0.827)$

$2.037^{\mathrm{b}}$

(1.000)

2.219

(1.494)

$-2.019^{\mathrm{c}}$

(1.150)

$-2.189^{\mathrm{c}}$

(1.256)

$0.735^{\mathrm{a}}$

$(0.206)$

$-0.025^{\mathrm{a}}$

(0.008)

$11.683^{\mathrm{a}}$

(1.408)

3242

0.045

Note: Regressions include information on gender, Hispanic, family composition, employer industry, unemployment insurance use and region of residence indicators. Robust standard errors in parentheses, ${ }^{\mathrm{a}},{ }^{\mathrm{b}}$ and ${ }^{\mathrm{c}}$ denote statistically different from zero at the $1 \%, 5 \%$ and $10 \%$ confidence levels, respectively. 
Table 7: Nonparametric difference in difference estimates of the impact of health insurance receipt after 1994 on individual specific time invariant unobserved productivity attributes $\theta_{\mathrm{i}}$

\begin{tabular}{|c|c|c|c|c|c|c|c|c|c|}
\hline \multirow[t]{2}{*}{ Sample } & \multicolumn{3}{|c|}{ Full Sample } & \multicolumn{3}{|c|}{$\begin{array}{l}\text { Health Insurance Pre } \\
\text { Displacement }\end{array}$} & \multicolumn{3}{|c|}{$\begin{array}{c}\text { No Health Insurance Pre } \\
\text { Displacement }\end{array}$} \\
\hline & All Ages & $\begin{array}{l}\text { Aged 20- } \\
\quad 44\end{array}$ & $\begin{array}{l}\text { Aged } 45- \\
\quad 64\end{array}$ & All Ages & $\begin{array}{l}\text { Aged 20- } \\
\quad 44\end{array}$ & $\begin{array}{l}\text { Aged 45- } \\
\quad 64\end{array}$ & All Ages & $\begin{array}{l}\text { Aged 20- } \\
44\end{array}$ & $\begin{array}{l}\text { Aged 45- } \\
\quad 64\end{array}$ \\
\hline $\begin{array}{l}\text { Health Insurance post } \\
\text { displacement }\left(\gamma_{2}\right)\end{array}$ & $\begin{array}{l}0.031^{\mathrm{a}} \\
(0.568)\end{array}$ & $\begin{array}{l}0.030^{\mathrm{a}} \\
(0.625)\end{array}$ & $\begin{array}{c}0.038^{\mathrm{a}} \\
(1.323)\end{array}$ & $\begin{array}{l}0.029^{\mathrm{a}} \\
(0.732)\end{array}$ & $\begin{array}{l}0.029^{\mathrm{a}} \\
(0.816)\end{array}$ & $\begin{array}{c}0.034^{\mathrm{b}} \\
(1.630)\end{array}$ & $\begin{array}{l}-0.010 \\
(0.976)\end{array}$ & $\begin{array}{c}-0.013 \\
(1.060)\end{array}$ & $\begin{array}{c}0.001 \\
(2.414)\end{array}$ \\
\hline $\begin{array}{l}\text { Health Insurance post } \\
\text { displacement after } 1994\left(\gamma_{3}\right)\end{array}$ & $\begin{array}{l}-0.042^{\mathrm{a}} \\
(0.887)\end{array}$ & $\begin{array}{l}-0.023^{\mathrm{a}} \\
(0.995)\end{array}$ & $\begin{array}{l}-0.100^{\mathrm{a}} \\
(1.921)\end{array}$ & $\begin{array}{l}-0.045^{\mathrm{a}} \\
(1.190)\end{array}$ & $\begin{array}{l}-0.035^{b} \\
(1.352)\end{array}$ & $\begin{array}{l}-0.077^{\mathrm{a}} \\
(2.479)\end{array}$ & $\begin{array}{l}-0.044^{\mathrm{a}} \\
(1.433)\end{array}$ & $\begin{array}{c}-0.012 \\
(1.579)\end{array}$ & $\begin{array}{l}-0.138^{\mathrm{a}} \\
(3.274)\end{array}$ \\
\hline $\begin{array}{l}\text { Indicator variable for Period } \\
\text { Following } 1994\left(\gamma_{4}\right)\end{array}$ & $\begin{array}{l}0.063^{\mathrm{a}} \\
(0.763)\end{array}$ & $\begin{array}{l}0.043^{\mathrm{a}} \\
(0.846)\end{array}$ & $\begin{array}{l}0.127^{\mathrm{a}} \\
(1.704)\end{array}$ & $\begin{array}{l}0.071^{\mathrm{a}} \\
(1.074)\end{array}$ & $\begin{array}{l}0.057^{\mathrm{a}} \\
(1.214)\end{array}$ & $\begin{array}{l}0.115^{\mathrm{a}} \\
(2.273)\end{array}$ & $\begin{array}{l}0.061^{\mathrm{a}} \\
(1.079)\end{array}$ & $\begin{array}{l}0.036^{\mathrm{a}} \\
(1.165)\end{array}$ & $\begin{array}{l}0.147^{\mathrm{a}} \\
(2.608)\end{array}$ \\
\hline Number of Observations & 14968 & 10930 & 4038 & 11216 & 8064 & 3152 & 3752 & 2866 & 886 \\
\hline Adjusted R-squared & 0.0063 & 0.0053 & 0.0140 & 0.0064 & 0.0053 & 0.0118 & 0.0117 & 0.0062 & 0.0454 \\
\hline
\end{tabular}

Note: Robust standard errors * $10 \mathrm{E}-3$ are in parentheses. ${ }^{\mathrm{a}},{ }^{\mathrm{b}}$ and ${ }^{\mathrm{c}}$ denote statistically different from zero at the $1 \%, 5 \%$ and $10 \%$ confidence levels, respectively. 